\title{
Produtividade de genótipos de milho em resposta à época de semeadura
}

\author{
Flávia Meinicke Nascimento ${ }^{1}$, Sílvio José Bicudo², José Guilherme Lança Rodrigues ${ }^{1}$, \\ Mariléia Barros Furtado ${ }^{1}$, Sérgio Campos ${ }^{3}$
}

\begin{abstract}
RESUMO
Com o objetivo de avaliar a interferência da época de semeadura de três cultivares de milho, com estádios fenológicos distintos, semeados em quatro épocas, foi desenvolvida a presente pesquisa. O experimento foi conduzido em condições de campo na Faculdade de Ciências Agronômicas da Universidade Estadual Paulista, Campus de Botucatu. O delineamento experimental foi o de blocos ao acaso com seis repetições, sendo consideradas causa de variação a composição genética dos cultivares de milho e épocas de semeadura. O experimento foi instalado segundo um modelo fatorial 3x4, com AL 34, ciclo normal, AG 9010, ciclo hiperprecoce e DKB 333B, ciclo semiprecoce e as épocas de semeadura agosto, outubro e dezembro de 2003 e fevereiro de 2004. Os dados foram submetidos à análise de variância e as médias comparadas pelo teste de Tukey a 5\% de probabilidade. A semeadura feita em fevereiro possibilitou uma emergência mais rápida, diferindo das demais épocas, independentemente, do cultivar. O número de folhas abaixo e acima da espiga, a população inicial e final são influenciados pela época de semeadura. Para a altura de plantas, a genética e a fisiologia dos cultivares preponderaram. A semeadura de fevereiro possibilitou encontrar diferenças significativas na produtividade, resultante da integração dos componentes de produção. Os cultivares de milho AL 34, AG 9010 e DKB 333B são dependentes da época de semeadura e do ciclo vegetativo de cada cultivar.
\end{abstract}

Palavras-chave: Zea mays L., morfologia, composição genética

\section{ABSTRACT}

\section{Productivity of maize genotypes in response to sowing time}

The objective of this study was to evaluate the influence of four sowing times on the yield of three maize cultivars with different phenological stages. Field experiments were carried out in the FCA/UNESP-Campus, Botucatu, São Paulo State, Brazil. The experiments were arranged in a randomized block design with six repetitions, considering maize genetic composition and sowing times as causes of variation. The treatments were arranged in a $3 \times 4$ factorial design, with three cultivars AL 34 (late cycle), AG 9010 (early cycle) and DKB 333B (medium-early cycle) planted in 4 sowing times, August, October and December 2003 and February 2004. Data were examined by analysis of variance and means were compared by the Tukey test at $5 \%$ probability level. Sowing in February provided a more rapid emergence, differing from the other times regardless of cultivar. The number of leaves above and below the ear and the initial and final population were influenced by sowing time. For plant height, genetics and physiology of cultivars predominated. Sowing in February allowed the identification of differences in productivity resulted from the integration of production components. Yield of cultivars AL 34, AG 9010 and DKB 333B depends on sowing time and vegetative cycle of each cultivar.

Key words: Zea mays, morphology, genetic composition.

Recebido para publicação em julho de 2009 e aprovado em março de 2011

${ }^{1}$ Engenheiros-Agrônomos, Doutores. Faculdade de Ciências Agronômicas, Universidade Estadual Paulista, Rua José Barbosa de Barros, 1780, 18610-307, Botucatu, São Paulo, Brasil. flaviameinicke@ hotmail.com (autora para correspondência).

${ }^{2}$ Engenheiro-Agrônomo, Doutor. Departamento de Produção Vegetal - Agricultura, Faculdade de Ciências Agronômicas, Universidade Estadual Paulista, Rua José Barbosa de Barros, 1780, 18610-307, Botucatu, São Paulo, Brasil. sjbicudo@fca.unesp.br

${ }^{3}$ Engenheiro-Agrônomo, Doutor. Departamento de Engenharia Rural, Faculdade de Ciências Agronômicas, Universidade Estadual Paulista, Rua José Barbosa de Barros, 1780, 18610-307, Botucatu, São Paulo, Brasil. seca@ fca.unesp.br 


\section{INTRODUÇÃO}

Existem no mercado híbridos de milho (Zea mays L.) com diferentes características fisiológicas que se adaptam melhor às condições de ambiente de diferentes regiões e que visam a atender as finalidades do agricultor.

O milho é uma planta de ciclo vegetativo variado, evidenciando desde cultivares extremamente precoces, cuja polinização pode ocorrer 30 dias após a emergência, até mesmo aqueles cujo ciclo vital pode alcançar 300 dias. Contudo, nas condições brasileiras, a cultura do milho apresenta ciclo que varia de 110 a 180 dias de acordo com a classificação dos cultivares em superprecoce, precoce ou normal, período compreendido entre a emergência e o florescimento (Fornasieri Filho, 2007).

Com o objetivo de atender às peculiaridades das diferentes regiões produtoras do Brasil, foram desenvolvidos novos sistemas de produção, e, para tanto, os melhoristas empenharam-se em obter híbridos de menor porte, precoces e mais eficientes na absorção de água, luz, temperatura e absorção de nutrientes. Tais características permitiram aperfeiçoar a utilização de germoplasmas de cultivares de milho de clima temperado.

Em geral, a semeadura da cultura se dá no mês de outubro, época tida como preferencial para esse procedimento, uma vez que faz coincidir o estádio em que a planta está com a máxima área foliar (espigamento) com os dias mais longos do ano (Embrapa, 2006). Em regiões em que a disponibilidade hídrica não é limitante, como é o caso das regiões sul e sudeste, observam-se menores potenciais de rendimento de grãos na semeadura precoce (agosto) em relação à época tida como preferencial para semeadura (Forsthofer et al., 2006). Esses menores potenciais são obtidos em função do menor desenvolvimento da planta, causado pelas menores temperaturas do ar e radiação solar incidente, que afetam a formação e a expressão dos componentes do rendimento e, consequentemente, o rendimento de grãos (Mundstock \& Silva, 2005); devendo-se ressaltar que tais fatores ambientais não se aplicam às regiões norte e nordeste. No entanto, o incremento na densidade de plantas pode-se constituir em estratégia eficiente para compensar a redução na produtividade na época de semeadura precoce, por aumentar o índice de área foliar, a interceptação de radiação solar e a capacidade fotossintética da comunidade de plantas (Silva et al., 1999).

O potencial de rendimento de grãos, a ser obtido em cada época de semeadura, dependerá principalmente da quantidade de radiação solar incidente, da eficiência de interceptação e da conversão da radiação interceptada em fitomassa, e da eficiência de partição de assimilados à estrutura de interesse econômico (Andrade, 1995). A quantidade de radiação incidente disponível varia com a posição geográfica de cada região produtora de grãos, ou seja, com sua latitude e altitude (Gardner et al., 1985; Stone et $a l ., 1999)$, e de acordo com a época de semeadura da cultura. A eficiência de interceptação da radiação e de sua conversão e partição em produtos orgânicos dependem de fatores climáticos, com destaque para temperatura do ar e disponibilidade hídrica; fatores edáficos, com ênfase na fertilidade natural, estrutura e textura do solo; e do manejo, destacando-se práticas culturais que interfiram sobre o arranjo de plantas.

O plantio do milho tem sido realizado em outra época como segunda cultura, denominada "safrinha". Entretanto nessa época, nas regiões sul e sudeste, o desempenho do milho não é satisfatório devido à falta de água e temperaturas desfavoráveis. Trabalhos têm mostrado que a "safrinha" exige genótipos de milho com elevado vigor de sementes, de plântulas, curto período para enchimento de grãos e resistência a diversas doenças (Fancelli \& Dourado Neto, 2000). No Mato Grosso a produção de milho "safrinha" significa mais de $40 \%$ da produção de segunda safra no Brasil, havendo forte potencial de crescimento devido às novas tecnologias, existindo potencial para produzir em mais de $50 \%$ da área.

Além dos fatores ambientais, é importante a escolha dos cultivares. As menores produtividades nos primeiros anos de avaliação do milho "safrinha", época referente à implantação de novo cultivar em determinada região, devese a falta inicial de informações sobre a adaptação de genótipos à modalidade de cultivo. Concluiu-se que a avaliação regional de cultivares de milho, bem como o lançamento de novos cultivares pelas empresas produtoras de sementes, tem contribuído efetivamente para o aumento de produtividade, principalmente na "safrinha". As épocas de semeadura interferem de maneira significativa em todas as características fenológicas e nos componentes de produção do milho, e cultivares com maior estabilidade geral, apresentam maior adaptação para "safrinha" (Quiessi, 1999).

Considerando a hipótese de que a cultura do milho depende da época de semeadura e do ciclo vegetativo de cada cultivar, a presente pesquisa objetivou avaliar a produtividade e os componentes de produção da cultura do milho que possam estar associados a esses fatores.

\section{MATERIAL E MÉTODOS}

O experimento foi conduzido na Faculdade de Ciências Agronômicas da Universidade Estadual Paulista, Botucatu, São Paulo, latitude de $22^{\circ} 51^{\prime}$ 'S, longitude de $48^{\circ} 26^{\prime}$ 'W e 740 metros de altitude, em solo classificado como Nitossolo Vermelho distroférrico (Embrapa, 1999), textura argilosa. O clima da região, segundo a classificação de Köppen, é do tipo Cfa, sendo definido como temperado (Mesotérmico), região constantemente úmida, tendo quatro ou mais meses com temperatura média superior a $10^{\circ} \mathrm{C}$, onde a temperatura do mês mais quente é igual ou superior a $22^{\circ} \mathrm{C}$. 
O solo da área experimental onde foi instalado o experimento apresentou as seguintes características químicas à profundidade de $0-20 \mathrm{~cm}: \mathrm{pH}$ em $\mathrm{CaCl}_{2}: 5,9 ; \mathrm{P}$ resina: 52,0 mg dm${ }^{3} ; \mathrm{K}: 5,1 \mathrm{mmol}_{\mathrm{c}} \mathrm{dm}^{3}$; M.O: $26 \mathrm{~g} \mathrm{dm}^{3} ; \mathrm{H}+\mathrm{Al}: 25$ mmol $\mathrm{dm}^{3} ; \mathrm{Ca}: 123 \mathrm{mmol}_{\mathrm{c}} \mathrm{dm}^{3} ; \mathrm{Mg}: 27 \mathrm{mmol}_{\mathrm{c}} \mathrm{dm}^{3} ; \mathrm{CTC}: 179$ mmol $\mathrm{dm}^{3}$; SB: $154 \mathrm{mmol}_{\mathrm{c}} \mathrm{dm}^{3}$; saturação de bases: $86 \%$.

$\mathrm{O}$ delineamento experimental foi o de blocos ao acaso com seis repetições, considerando causa de variação os cultivares de milho e as épocas de semeadura. O experimento foi instalado segundo um modelo fatorial $3 \times 4$ e as parcelas apresentavam $10 \mathrm{~m}$ de comprimento. Os dados foram submetidos à análise de variância e as médias comparadas pelo teste de Tukey a $5 \%$ de probabilidade.

Os tratamentos foram constituídos por cultivares e épocas de semeadura sendo: AL 34, variedade de porte alto, ciclo vegetativo normal; AG 9010, híbrido simples, de porte baixo e ciclo hiperprecoce e DKB 333B, híbrido triplo, porte intermediário, ciclo semiprecoce. As épocas de semeadura foram agosto, outubro e dezembro de 2003 e fevereiro de 2004. As parcelas foram compostas de quatro linhas, espaçadas de $0,85 \mathrm{~m}$, com $10 \mathrm{~m}$ de comprimento. As sementes foram distribuídas manualmente em sulcos previamente abertos, onde a adubação de plantio foi de $214 \mathrm{~kg} \mathrm{ha}^{-1}$ do adubo formulado 04-14-08, equivalente a $8,56 \mathrm{~kg} \mathrm{ha}^{-1} \mathrm{de} \mathrm{N}, 29,96 \mathrm{~kg} \mathrm{ha}^{-1} \mathrm{de}_{2} \mathrm{O}_{5}$ e $17,12 \mathrm{~kg}$ $\mathrm{ha}^{-1}$ de $\mathrm{K}_{2} \mathrm{O}$. A cobertura foi realizada aos 15 dias após a emergência no estádio de 3 a 4 folhas, sendo utilizados $100 \mathrm{~kg} \mathrm{ha}^{-1} \mathrm{de} \mathrm{N}$, tendo como fonte a ureia.

O milho foi semeado nos dias 19/08 ( $1^{\mathrm{a}}$ época); $15 / 10$ ( $2^{a}$ época); 17/12 ( $3^{a}$ época) e 16/02 (4 época) e colhido nos dias 15/01( $1^{\mathrm{a}}$ época); 17/03 ( $2^{\mathrm{a}}$ época);15/05 (3ª época); 18/07 (4 época). A colheita foi realizada manualmente em todas as épocas. A irrigação foi utilizada quando necessária. Foram realizadas todas as práticas usuais para controle fitossanitário.

As Figuras 1 e 2 contêm os dados de precipitação pluvial ( $\mathrm{mm}$ mês $\left.{ }^{-1}\right)$ e temperaturas mínima, máxima e média mensais $\left({ }^{\circ} \mathrm{C}\right)$ dos meses de agosto de 2003 a julho de 2004.

As avaliações realizadas foram: índice de velocidade de emergência; população inicial e final de plantas $\mathrm{ha}^{-1}$; número médio de folhas por planta abaixo e acima da espiga; altura de plantas; índice de área foliar; índice de espigas; número médio de espigas; comprimento, diâmetro e número de fileiras por espiga; massa de 1000 grãos e produtividade. O Índice de velocidade de emergência foi obtido, contando-se, desde o início da emergência, o número de plantas emergidas em três linhas por parcela de dois metros, fixas até a última contagem, diariamente, até se obter o número constante de plantas emergidas, segundo método descrito por Maguire (1962), utilizando-se a equação:

$$
\operatorname{IVE}=\left(\mathrm{E}_{1} / \mathrm{N}_{1}\right)+\left(\mathrm{E}_{2} / \mathrm{N}_{2}\right)+\ldots(\mathrm{En} / \mathrm{Nn})
$$

Emque:

IVE = Índice de Velocidade de Emergência

$\mathrm{E}_{1} \ldots \mathrm{En}=$ Número de plantas normais computado da primeira até a última contagem

$\mathrm{N}_{1} \ldots \mathrm{Nn}=$ Número de dias da semeadura da primeira até a última contagem

A população inicial foi feita contando-se o número total de plantas presentes em três linhas de dois metros, onde posteriormente foi contada a população final. $\mathrm{O}$ número médio de folhas por planta abaixo e acima da espiga foi feito contando-se todas as folhas abaixo e acima da espiga por ocasião do florescimento feminino, utilizando-se dez plantas por parcela. A altura das plantas foi medida no final do ciclo e considerada a distância do solo até a inserção da folha bandeira, em metros, nas três linhas centrais, utilizando-se dez plantas por parcela. O índice de área foliar (IAF) foi medido retirando-se todas as folhas da planta em cinco plantas por parcela, e feita a leitura com o equipamento Area Meter Leaf, Li-Cor, model 3100, Lincoln, Nebraska, USA. O índice de espigas foi calculado dividindo-se o número de espigas pelo número de plantas, presentes nas três linhas centrais de cada parcela. Foi contado o número

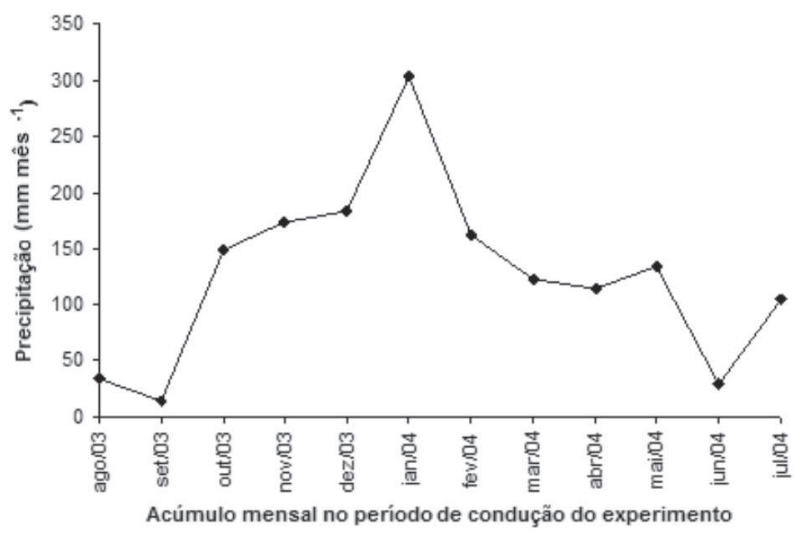

Figura 1. Acúmulo mensal da precipitação pluvial ( $\left.\mathrm{mm} \mathrm{mês}^{-1}\right)$, registrada durante a condução dos experimentos, em Botucatu, São Paulo.

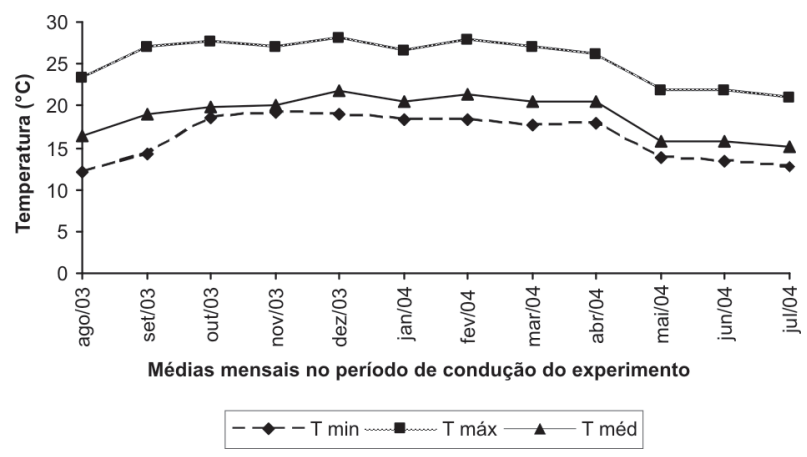

Figura 2. Temperaturas $\left({ }^{\circ} \mathrm{C}\right)$ máxima, mínima e média mensais, registradas durante a condução dos experimentos, em Botucatu, São Paulo.

Rev. Ceres, Viçosa, v. 58, n.2, p. 193-201, mar/abr, 2011 
de espigas presentes nas três linhas centrais de cada parcela, após a colheita. Foi medido o comprimento e o diâmetro de espigas e contado o número de fileiras por espiga, utilizando-se para tanto dez espigas por parcela. Após a trilhagem do milho, foi realizada a contagem de quatro repetições de 100 grãos por parcela, sendo posteriormente transformados para 1000 grãos e tendo a massa ajustada a 13\% do teor de água. Para determinação da produtividade foram colhidas todas as espigas presentes nas três linhas centrais de cada parcela. O resultado foi expresso em $\mathrm{kg} \mathrm{ha}^{-1}$, sendo o teor de água ajustado a $13 \%$.

\section{RESULTADOS E DISCUSSÃO}

O cultivar AG 9010 mostrou-se o mais vigoroso em todas as épocas de semeadura, e foi também independentemente da época de semeadura aquele que mais rapida- mente emergiu diferindo significativamente dos demais (Tabela 1). Em contraste com esta situação, o cultivar AL 34 foi sempre o que apresentou a menor velocidade de emergência, refletindo menor vigor; como as sementes têm origem diferente, isso pode estar associado à qualidade fisiológica de cada lote de semente e não à época de plantio. A semeadura feita em fevereiro possibilitou uma emergência mais rápida, diferindo das demais épocas independentemente do cultivar. Tal fato pode ser explicado pela maior disponibilidade hídrica e térmica no período compreendido entre a semeadura e emergência das plântulas.

A época de semeadura interferiu de maneira significativa tanto na população inicial, quanto na população final (Tabela 1). Deve ser destacado que a semeadura feita em agosto foi aquela em que as populações mais se aproxi-

Tabela 1. Índice de Velocidade de Emergência, população inicial e final de plantas ha-1 ${ }^{-1}$ de três cultivares de milho, em quatro épocas de semeadura

\begin{tabular}{|c|c|c|c|c|c|}
\hline \multirow{2}{*}{ Cultivar } & \multicolumn{5}{|c|}{ Época de semeadura } \\
\hline & Agosto/03 & Outubro/03 & Dezembro/03 & Fevereiro/04 & Média \\
\hline & \multicolumn{5}{|c|}{ Índice de Velocidade de Emergência } \\
\hline AL 34 & 7,35 Bb & $9,36 \mathrm{Ab}$ & $6,77 \mathrm{Bb}$ & $10,23 \mathrm{Ab}$ & $8,43 \mathrm{c}$ \\
\hline AG 9010 & $10,79 \mathrm{BCa}$ & $11,78 \mathrm{Ba}$ & $10,28 \mathrm{Ca}$ & $13,27 \mathrm{Aa}$ & $11,53 \mathrm{a}$ \\
\hline DKB 333 B & $7,10 \mathrm{Cb}$ & $9,75 \mathrm{Bb}$ & $9,58 \mathrm{Ba}$ & $13,65 \mathrm{Aa}$ & $10,02 \mathrm{~b}$ \\
\hline Média & $8,41 \mathrm{C}$ & $10,30 \mathrm{~B}$ & $8,88 \mathrm{C}$ & $12,38 \mathrm{~A}$ & \\
\hline \multicolumn{6}{|l|}{ Teste $\mathrm{F} p<0,05$} \\
\hline Cultivar & $* *$ & $* *$ & $* *$ & $* *$ & $* *$ \\
\hline Época & & & & & $* *$ \\
\hline Época x Cultivar & & & & & $* *$ \\
\hline \multirow[t]{2}{*}{$\mathrm{CV}(\%)$} & & & & & 8,74 \\
\hline & \multicolumn{5}{|c|}{ População inicial de plantas ha' } \\
\hline AL 34 & 47059 & 44445 & 39543 & 39216 & $42565 \mathrm{~b}$ \\
\hline AG 9010 & 46079 & 46732 & 45425 & 43465 & $45425 \mathrm{ab}$ \\
\hline DKB 333 B & 51634 & 45751 & 44118 & 43791 & $46324 \mathrm{a}$ \\
\hline Média & $48257 \mathrm{~A}$ & $45643 \mathrm{AB}$ & $43029 \mathrm{~B}$ & $42157 \mathrm{~B}$ & \\
\hline \multicolumn{6}{|l|}{ Teste $\mathrm{F} p<0,05$} \\
\hline Cultivar & n.s & n.s & n.s & n.s & $* *$ \\
\hline Época & & & & & $* *$ \\
\hline Época x Cultivar & & & & & n.s \\
\hline \multirow[t]{2}{*}{$\mathrm{CV}(\%)$} & & & & & 9,22 \\
\hline & \multicolumn{5}{|c|}{ População final de plantas ha-1 } \\
\hline AL 34 & 46079 & 40196 & 35948 & 35294 & $39379 \mathrm{~b}$ \\
\hline AG 9010 & 46079 & 42811 & 38562 & 39043 & $41624 \mathrm{~b}$ \\
\hline DKB 333 B & 49347 & 44445 & 43791 & 43791 & $45343 \mathrm{a}$ \\
\hline Média & $47168 \mathrm{~A}$ & $42484 \mathrm{~B}$ & 39434 B & 39376 B & \\
\hline \multicolumn{6}{|l|}{ Teste F p $<0,05$} \\
\hline Cultivar & n.s & n.s & n.s & n.s & $* *$ \\
\hline Época & & & & & $* *$ \\
\hline Época x Cultivar & & & & & n.s \\
\hline $\mathrm{CV}(\%)$ & & & & & 11,26 \\
\hline
\end{tabular}

Médias seguidas por mesma letra, minúsculas na coluna e maiúsculas na linha não diferem entre si pelo teste de Tukey a 5\% de probabilidade. n.s. -não significativo, * -efeito significativo $5 \%$, ** - efeito significativo $1 \%$.

Rev. Ceres, Viçosa, v. 58, n.2, p. 193-201, mar/abr, 2011 
maram da população programada que era de 50.000 plantas ha-1 ao final do ciclo, sendo feitas irrigações quando necessário. O híbrido DKB 333B, independentemente da época de semeadura, apresentou o melhor desempenho, diferindo dos demais cultivares tanto no início quanto no final do ciclo.

O número de folhas abaixo da espiga tem sido usado como um referencial do grau de temperalização dos cultivares no Brasil, ou seja, materiais adaptados a menor número de unidades calóricas (Viegas \& Peeten, 1987). A época de semeadura influiu no número de folhas postas pelas plantas abaixo da espiga (Tabela 2). A semeadura feita em fevereiro apresentou o menor número de folhas abaixo da espiga. Os cultivares utilizados na presente pesquisa apresentaram diferentes graus de temperalização expressos particularmente pela duração de seus ciclos. De certa forma, o número de folhas abaixo da espiga refletiu a situação acima citada, visto que o cultivar AG 9010, considerado hiperprecoce, foi o cultivar, que em todas as épocas de semeadura melhor representou a situação.

A época de semeadura influi no número de folhas acima da espiga (Tabela 2). A semeadura realizada em dezembro possibilitou o desenvolvimento do maior número de folhas acima da espiga independentemente do cultivar. A semeadura de fevereiro impôs uma restrição significativa ao aparecimento de folhas, sendo a época em que as plan- tas apresentaram o menor número acima da espiga. O cultivar AG 9010, na média das épocas, apresentou o menor número de folhas acima da espiga, refletindo de certa forma sua condição de cultivar hiperprecoce.

Dentre os inúmeros fatores que interferem na altura final das plantas de milho, a época de semeadura pode ser considerada como sendo pouco importante. Os cultivares superprecoces diferenciam o seu pendão floral mais rapidamente, alcançando a fase de florescimento com menor número de folhas, menor área foliar e porte mais baixo do que os cultivares tardios, que passam maior tempo vegetando antes de transformarem o seu ponto de crescimento num primórdio floral (Sangoi et al., 2001). Na presente pesquisa, apenas na semeadura feita no mês de fevereiro foi possível perceber uma redução significativa da altura (Tabela 3). Aspectos ligados à genética e à fisiologia dos cultivares preponderaram, considerando que o cultivar AG 9010 apresentou menor desenvolvimento, independentemente da época de semeadura. Silva et al. (1996), estudando a resposta de genótipos de milho à densidade de plantas, em três épocas de semeadura, observaram que a altura de plantas e altura de inserção da espiga foram mais elevadas na semeadura de outubro em relação às de agosto e dezembro e, segundo estes autores, os rendimentos de grãos só foram alterados pela época de semeadura; na semeadura de outubro, os rendimen-

Tabela 2. Número médio de folhas por planta abaixo e acima da espiga no florescimento feminino, de três cultivares de milho, em quatro épocas de semeadura

\begin{tabular}{|c|c|c|c|c|c|}
\hline \multirow{2}{*}{ Cultivar } & \multicolumn{5}{|c|}{ Época de semeadura } \\
\hline & Agosto/03 & Outubro/03 & Dezembro/03 & Fevereiro/04 & Média \\
\hline & \multicolumn{5}{|c|}{ Número médio de folhas por planta abaixo da espiga } \\
\hline AL 34 & 7,73 Aa & $7,66 \mathrm{Aa}$ & $7,30 \mathrm{Aa}$ & $6,13 \mathrm{Ba}$ & $7,20 \mathrm{a}$ \\
\hline AG 9010 & $6,56 \mathrm{Ab}$ & $6,93 \mathrm{Ab}$ & $6,33 \mathrm{Ab}$ & $5,46 \mathrm{Bb}$ & $6,32 \mathrm{~b}$ \\
\hline DKB 333 B & $8,10 \mathrm{Aa}$ & 7,46 ABab & $7,30 \mathrm{Ba}$ & $4,93 \mathrm{Cb}$ & $6,95 \mathrm{a}$ \\
\hline Média & $7,46 \mathrm{~A}$ & $7,35 \mathrm{~A}$ & $6,97 \mathrm{~B}$ & $5,51 \mathrm{C}$ & \\
\hline \multicolumn{6}{|l|}{ Teste F p $<0,05$} \\
\hline Cultivar & $* *$ & $*$ & $* *$ & $* *$ & $* *$ \\
\hline Época & & & & & $* *$ \\
\hline Época x Cultivar & & & & & $* *$ \\
\hline \multirow[t]{2}{*}{$\mathrm{CV}(\%)$} & & & & & 6,08 \\
\hline & \multicolumn{5}{|c|}{ Número médio de folhas por planta acima da espiga } \\
\hline AL 34 & 5,73 & 6,30 & 6,40 & 5,76 & $6,05 \mathrm{~b}$ \\
\hline AG 9010 & 5,63 & 5,66 & 5,83 & 5,16 & $5,57 \mathrm{c}$ \\
\hline DKB 333 B & 6,50 & 6,63 & 6,73 & 5,80 & $6,41 \mathrm{a}$ \\
\hline Média & $5,95 \mathrm{~B}$ & $6,20 \mathrm{AB}$ & $6,32 \mathrm{~A}$ & $5,57 \mathrm{C}$ & \\
\hline \multicolumn{6}{|l|}{ Teste F $\mathrm{p}<0,05$} \\
\hline Cultivar & n.s & n.s & n.s & n.s & $* *$ \\
\hline Época & & & & & $* *$ \\
\hline Época x Cultivar & & & & & n.s \\
\hline $\mathrm{CV}(\%)$ & & & & & 5,70 \\
\hline
\end{tabular}

Médias seguidas por mesma letra, minúsculas na coluna e maiúsculas na linha não diferem entre si pelo teste de Tukey a 5\% de probabilidade. n.s. -não significativo, * -efeito significativo $5 \%$, ** - efeito significativo $1 \%$. 
Tabela 3. Altura média de plantas (m) e Índice de Área Foliar, de três cultivares de milho, em quatro épocas de semeadura

\begin{tabular}{|c|c|c|c|c|c|}
\hline \multirow{2}{*}{ Cultivar } & \multicolumn{5}{|c|}{ Época de semeadura } \\
\hline & Agosto/03 & Outubro/03 & Dezembro/03 & Fevereiro/04 & Média \\
\hline & \multicolumn{5}{|c|}{ Altura média de plantas $(\mathrm{m})$} \\
\hline AL 34 & 183,94 & 187,01 & 187,59 & 138,60 & $174,28 \mathrm{a}$ \\
\hline AG 9010 & 153,91 & 156,25 & 142,71 & 111,87 & $141,19 \mathrm{c}$ \\
\hline DKB 333 B & 165,16 & 158,33 & 170,79 & 118,20 & $153,12 \mathrm{~b}$ \\
\hline Média & $167,67 \mathrm{~A}$ & $162,20 \mathrm{~A}$ & $167,03 \mathrm{~A}$ & $122,89 \mathrm{~B}$ & \\
\hline \multicolumn{6}{|l|}{ Teste F p $<0,05$} \\
\hline Cultivar & n.s & n.s & n.s & n.s & $* *$ \\
\hline Época & & & & & $* *$ \\
\hline Época x Cultivar & & & & & n.s \\
\hline $\mathrm{CV}(\%)$ & & & & & 6,75 \\
\hline \multicolumn{6}{|c|}{ Índice de Área Foliar } \\
\hline AL 34 & 3,77 & 3,44 & 1,89 & 1,36 & $2,61 \mathrm{~b}$ \\
\hline AG 9010 & 2,74 & 2,69 & 1,60 & 1,03 & $2,02 \mathrm{c}$ \\
\hline DKB 333 B & 4,06 & 4,05 & 2,57 & 1,75 & $3,09 \mathrm{a}$ \\
\hline Média & $3,50 \mathrm{~A}$ & $3,39 \mathrm{~A}$ & $2,02 \mathrm{~B}$ & $1,38 \mathrm{C}$ & \\
\hline \multicolumn{6}{|l|}{ Teste F p $<0,05$} \\
\hline Cultivar & n.s & n.s & n.s & n.s & $* *$ \\
\hline Época & & & & & $* *$ \\
\hline Época x Cultivar & & & & & n.s \\
\hline $\mathrm{CV}(\%)$ & & & & & 14,35 \\
\hline
\end{tabular}

Médias seguidas por mesma letra, minúsculas na coluna e maiúsculas na linha não diferem entre si pelo teste de Tukey a $5 \%$ de probabilidade. n.s. -não significativo, * -efeito significativo $5 \%$, ** - efeito significativo $1 \%$.

Tabela 4. Índice de espigas e número médio de espigas ha ${ }^{-1}$, de três cultivares de milho, em quatro épocas de semeadura

\begin{tabular}{|c|c|c|c|c|c|}
\hline \multirow{2}{*}{ Cultivar } & \multicolumn{5}{|c|}{ Época de semeadura } \\
\hline & Agosto/03 & Outubro/03 & Dezembro/03 & Fevereiro/04 & Média \\
\hline & \multicolumn{5}{|c|}{ Índice de espigas } \\
\hline AL 34 & 0,95 & 1,07 & 1,14 & 0,84 & $1,00 \mathrm{a}$ \\
\hline AG 9010 & 0,97 & 1,02 & 1,07 & 0,96 & $1,00 \mathrm{a}$ \\
\hline DKB 333 B & 0,99 & 0,98 & 1,04 & 0,82 & $0,96 \mathrm{a}$ \\
\hline Média & $0,97 \mathrm{~B}$ & $1,02 \mathrm{AB}$ & $1,08 \mathrm{~A}$ & $0,87 \mathrm{C}$ & \\
\hline \multicolumn{6}{|l|}{ Teste F p $<0,05$} \\
\hline Cultivar & n.s & n.s & n.s & n.s & n.s \\
\hline Época & & & & & $* *$ \\
\hline Época x Cultivar & & & & & n.s \\
\hline \multirow[t]{2}{*}{$\mathrm{CV}(\%)$} & & & & & 10,96 \\
\hline & \multicolumn{5}{|c|}{ Número médio de espigas ha ${ }^{-1}$} \\
\hline AL 34 & 43330 & 39118 & 34506 & 26077 & $35759 \mathrm{~b}$ \\
\hline AG 9010 & 43724 & 42842 & 35295 & 34606 & 39118 a \\
\hline DKB 333 B & 46959 & 39606 & 41271 & 31271 & 39777 a \\
\hline Média & $44671 \mathrm{~A}$ & $40518 \mathrm{~B}$ & 37024 B & $30653 \mathrm{C}$ & \\
\hline \multicolumn{6}{|l|}{ Teste $\mathrm{F} p<0,05$} \\
\hline Cultivar & n.s & n.s & n.s & n.s & $* *$ \\
\hline Época & & & & & $* *$ \\
\hline Época x Cultivar & & & & & n.s \\
\hline$\overline{\mathrm{CV}(\%)}$ & & & & & 11,62 \\
\hline
\end{tabular}

Médias seguidas por mesma letra, minúsculas na coluna e maiúsculas na linha não diferem entre si pelo teste de Tukey a 5\% de probabilidade. n.s. -não significativo, * -efeito significativo $5 \%$, ** - efeito significativo $1 \%$.

Rev. Ceres, Viçosa, v. 58, n.2, p. 193-201, mar/abr, 2011 
tos foram de 14,5 e 46,7\% superiores aos obtidos nas épocas de agosto a dezembro, respectivamente. Quanto mais alta a planta de milho, provavelmente maior será seu potencial de produção e maior aporte fotossintético para as folhas. As temperaturas diurnas e noturnas mais altas aumentam a unidade calórica, reduzindo o ciclo, principalmente em dezembro e janeiro.

O índice de área foliar, por expressar a proporção de cobertura do solo, implica importante fator a ser considerado para a definição das práticas de manejo (Guimarães et $a l .$, 2002). Este índice é utilizado como parâmetro nos estudos do desenvolvimento vegetal e análise de crescimento e é de grande importância na avaliação de características agronômicas na cultura do milho (Afférri et al., 2002).

Inúmeros trabalhos indicam ser cinco o índice de área foliar ideal para a cultura do milho. No presente trabalho, a época de semeadura influenciou o índice de área foliar: as semeaduras realizadas em agosto e outubro proporcionaram os índices mais elevados, que diferiram significativamente dos índices obtidos nas demais épocas (Tabela 3), o que demonstra que o índice de área foliar é fortemente influenciado pelo cultivar. Nesta pesquisa, embora abaixo do ideal, o cultivar DKB 333 B apresentou independentemente da época de semeadura o maior índice de área foliar. Provavelmente, pelo ciclo mais longo (normal) e que é afetado pelo calor, mas não chega a perder tanto quanto um hiperprecoce.

$\mathrm{O}$ índice de espigas reflete a adequação da população de plantas e a disponibilidade de fatores de ambiente, como a luz. Quando este se aproxima de 1,00, os fatores população e ambiente parecem estar melhor ajustados.

Tabela 5.Comprimento e diâmetro médio de espigas $(\mathrm{cm})$ e número de fileiras por espiga, de três cultivares de milho, em quatro épocas de semeadura

\begin{tabular}{|c|c|c|c|c|c|}
\hline \multirow{2}{*}{ Cultivar } & \multicolumn{5}{|c|}{ Época de semeadura } \\
\hline & Agosto/03 & Outubro/03 & Dezembro/03 & Fevereiro/04 & Média \\
\hline & \multicolumn{5}{|c|}{ Comprimento médio de espigas $(\mathrm{cm})$} \\
\hline AL 34 & 14,65 & 16,25 & 16,60 & 10,38 & $14,47 \mathrm{~b}$ \\
\hline AG 9010 & 16,23 & 15,76 & 15,70 & 10,03 & $14,43 \mathrm{~b}$ \\
\hline DKB 333 B & 16,05 & 17,53 & 17,5 & 11,80 & $15,73 \mathrm{a}$ \\
\hline Média & $15,64 \mathrm{~B}$ & $16,51 \mathrm{AB}$ & $16,61 \mathrm{~A}$ & $10,73 \mathrm{C}$ & \\
\hline \multicolumn{6}{|l|}{ Teste $\mathrm{F} p<0,05$} \\
\hline Cultivar & n.s & n.s & n.s & n.s & $* *$ \\
\hline Época & & & & & $* *$ \\
\hline Época x Cultivar & & & & & n.s \\
\hline \multirow[t]{2}{*}{$\mathrm{CV}(\%)$} & & & & & 7,23 \\
\hline & \multicolumn{5}{|c|}{ Diâmetro médio de espigas (cm) } \\
\hline AL 34 & 4,41 & 4,61 & 4,60 & 3,83 & $4,36 \mathrm{a}$ \\
\hline AG 9010 & 4,65 & 4,51 & 4,45 & 3,73 & $4,33 \mathrm{a}$ \\
\hline DKB 333 B & 4,58 & 4,63 & 4,58 & 3,88 & $4,42 \mathrm{a}$ \\
\hline Média & $4,55 \mathrm{~A}$ & $4,58 \mathrm{~A}$ & $4,54 \mathrm{~A}$ & $3,81 \mathrm{~B}$ & \\
\hline \multicolumn{6}{|l|}{ Teste $\mathrm{F} p<0,05$} \\
\hline Cultivar & n.s & n.s & n.s & n.s & n.s \\
\hline Época & & & & & $* *$ \\
\hline Época x Cultivar & & & & & n.s \\
\hline \multirow[t]{2}{*}{$\mathrm{CV}(\%)$} & & & & & 3,99 \\
\hline & \multicolumn{5}{|c|}{ Número de fileiras por espiga } \\
\hline AL 34 & 13,43 & 14,56 & 13,06 & 12,61 & $13,42 \mathrm{~b}$ \\
\hline AG 9010 & 14,50 & 14,16 & 14,13 & 13,53 & $14,08 \mathrm{a}$ \\
\hline DKB 333 B & 13,55 & 13,71 & 13,33 & 13,20 & $13,45 \mathrm{~b}$ \\
\hline Média & $13,82 \mathrm{~A}$ & $14,15 \mathrm{~A}$ & $13,51 \mathrm{AB}$ & $13,11 \mathrm{~B}$ & \\
\hline \multicolumn{6}{|l|}{ Teste F p $<0,05$} \\
\hline Cultivar & n.s & n.s & n.s & n.s & $* *$ \\
\hline Época & & & & & $* *$ \\
\hline Época x Cultivar & & & & & n.s \\
\hline $\mathrm{CV}(\%)$ & & & & & 5,72 \\
\hline
\end{tabular}

Médias seguidas por mesma letra, minúsculas na coluna e maiúsculas na linha não diferem entre si pelo teste de Tukey a 5\% de probabilidade. n.s. -não significativo, * -efeito significativo $5 \%$, ** - efeito significativo $1 \%$. 
Este índice na média dos cultivares, independentemente da época, não difere estatísticamente e encontra-se dentro da faixa considerada adequada (Tabela 4). A época de semeadura interferiu de maneira significativa no índice de espigas, sendo a instalação de fevereiro aquela que obteve o menor índice, a despeito da população final de plantas também ter sido a menor, provavelmente em decorrência de ataque de pragas.

Pode ser observado que a variação do número de espigas por hectare (Tabela 4) acompanha a variação do número de plantas por hectare no final do ciclo. Pode ser dito que a época de semeadura interferiu no número de espigas, sendo que a semeadura de agosto possibilitou o maior número destas. Quanto aos cultivares, o AL 34, na média das quatro épocas de semeadura foi o que menos espigas produziu por hectare.

Também na semeadura de fevereiro, foi obtido o menor comprimento de espigas (Tabela 5), revelando ter sido a época de semeadura fator importante na definição destas duas características. O cultivar DKB 333 B apresentou o maior comprimento de espiga, independentemente da época de semeadura.

Os cultivares não apresentaram variações significativas no diâmetro médio de espigas, sendo que a semeadura realizada em fevereiro foi aquela em que o diâmetro médio das espigas foi o menor independentemente do cultivar (Tabela 5).
O híbrido AG 9010, independentemente da época de semeadura, foi superior, quanto ao número de fileiras por espiga (Tabela 5), evidenciando ser esta uma característica bastante dependente do genótipo, tendo, também, na época de fevereiro, apresentado menores valores para esta característica.

A massa de 1000 grãos foi menor na semeadura feita em fevereiro (Tabela 6), refletindo como os demais parâmetros, a interferência da época de semeadura neste que é um dos componentes de produção mais importantes. O híbrido AG 9010, independentemente da época, foi o que apresentou a menor massa de 1000 grãos, característica esta associada ao genoma.

A produtividade resultante da integração dos diversos parâmetros considerados componentes de produção, expressa pela semeadura de fevereiro, de maneira inequívoca, a interferência da época de semeadura, nos componentes de produção e as consequências desta interferência na produtividade (Tabela 6).

Forsthofer et al. (2006), estudando o desempenho agronômico do milho em diferentes níveis de manejo e épocas de semeadura, constataram: que a elevação no rendimento de grãos com a melhoria do nível de manejo está associada, principalmente, à elevação do número de espigas e de grãos por área; e que nas semeaduras de agosto e outubro é possível associar máxima eficiência técnica com máxima eficiência econômica, por meio da

Tabela 6. Massa de 1000 grãos (g) e produtividade do milho $\left(\mathrm{kg} \mathrm{ha}^{-1}\right)$, de três cultivares de milho, em quatro épocas de semeadura

\begin{tabular}{|c|c|c|c|c|c|}
\hline \multirow{2}{*}{ Cultivar } & \multicolumn{5}{|c|}{ Época de semeadura } \\
\hline & Agosto/03 & Outubro/03 & Dezembro/03 & Fevereiro/04 & Média \\
\hline & \multicolumn{5}{|c|}{ Massa de 1000 grãos (g) } \\
\hline AL 34 & 342,0 & 324,5 & 366,6 & 241,5 & $318,6 \mathrm{ab}$ \\
\hline AG 9010 & 357,5 & 321,0 & 339,5 & 231,7 & $312,4 \mathrm{~b}$ \\
\hline DKB 333 B & 376,5 & 332,8 & 358,0 & 249,1 & 329,1 a \\
\hline Média & $358,6 \mathrm{~A}$ & $326,1 \mathrm{~B}$ & $354,7 \mathrm{~A}$ & $240,8 \mathrm{C}$ & \\
\hline \multicolumn{6}{|l|}{ Teste F p $<0,05$} \\
\hline Cultivar & n.s & n.s & n.s & n.s & $* *$ \\
\hline Época & & & & & $* *$ \\
\hline Época x Cultivar & & & & & n.s \\
\hline \multirow[t]{2}{*}{$\mathrm{CV}(\%)$} & & & & & 5,35 \\
\hline & \multicolumn{5}{|c|}{ Produtividade do milho $\left(\mathrm{kg} \mathrm{ha}^{-1}\right)$} \\
\hline AL 34 & $5022,00 \mathrm{Ab}$ & $5487,16 \mathrm{Aa}$ & $5058,50 \mathrm{Ab}$ & $1582,66 \mathrm{Ba}$ & $4287,58 \mathrm{~b}$ \\
\hline AG 9010 & $6293,33 \mathrm{Aa}$ & $5842,50 \mathrm{ABa}$ & $4751,50 \mathrm{Bb}$ & $2150,50 \mathrm{Ca}$ & $4759,45 \mathrm{ab}$ \\
\hline DKB 333 B & $6566,50 \mathrm{Aa}$ & $5661,66 \mathrm{Aa}$ & $6455,33 \mathrm{Aa}$ & $2243,50 \mathrm{Ba}$ & $5231,75 \mathrm{a}$ \\
\hline Média & $5960,61 \mathrm{~A}$ & $5663,77 \mathrm{~A}$ & $5421,77 \mathrm{~A}$ & 1992,22 B & \\
\hline \multicolumn{6}{|l|}{ Teste $\mathrm{F} p<0,05$} \\
\hline Cultivar & $* *$ & n.s & $* *$ & n.s & $* *$ \\
\hline Época & & & & & $* *$ \\
\hline Época x Cultivar & & & & & $*$ \\
\hline$\overline{\mathrm{CV}(\%)}$ & & & & & 16,37 \\
\hline
\end{tabular}

Médias seguidas por mesma letra, minúsculas na coluna e maiúsculas na linha não diferem entre si pelo teste de Tukey a $5 \%$ de probabilidade. n.s. -não significativo, * -efeito significativo $5 \%$, ** - efeito significativo $1 \%$.

Rev. Ceres, Viçosa, v. 58, n.2, p. 193-201, mar/abr, 2011 
melhoria do nível de manejo e da adoção de cultivares com maior potencial de rendimento. Estes autores observaram também que, na semeadura tardia (dezembro), não há retorno econômico à utilização de sistemas de manejo destinados a potencializar o rendimento de grãos, o que não ocorreu no presente estudo pois a época de semeadura de dezembro apresentou boas produtividades (Tabela 6).

Yuyama et al. (2006), estudando épocas de plantio (início e final de novembro e início de dezembro) e cultivares de milho na região de Humaitá, Amazonas, verificaram que a primeira e a segunda época proporcionaram maior produção do que a terceira, indicando que o plantio tardio diminuiu a produção de grãos de milho, o que nos informa que embora as condições ambientais da região norte sejam diferentes das da região sudeste, o plantio tardio também resulta em menores produtividades, como a "safrinha" desta pesquisa (época de fevereiro, Tabela 6).

\section{CONCLUSÕES}

A semeadura de fevereiro, dos cultivares de milho AL 34, AG 9010 e DKB 333B, possibilita encontrar diferenças significativas na produtividade, resultante da integração dos componentes de produção.

\section{REFERÊNCIAS}

Afférri FS, Dourado Neto D \& Fancelli AL (2002) Relação entre IAF e altura de planta em três híbridos de milho. In: $24^{\circ}$ Congresso Nacional de Milho e Sorgo, Florianópolis. Anais, EMBRAPA/ CNPMS. p.108

Andrade FH (1995) Analysis of growth and yield of maize, sunflower and soybean grown at Balcarce, Argentina. Field Crops Research, 41:1-12.

Embrapa - Centro Nacional de Pesquisa de Solos (1999) Sistema brasileiro de classificação de solos. $2^{\text {a }}$ ed. Brasília, Embrapa Produção de Informação, Rio de Janeiro EMBRAPA Solos. 412p.

Embrapa - Centro Nacional de Pesquisas de Solos (2006) Indicações técnicas para o cultivo de milho e de sorgo no Rio Grande do Sul - 2006/2007. Passo Fundo, Embrapa Trigo. 184p.

Fancelli AL \& Dourado Neto D (2000) Produção de milho. $2^{\mathrm{a}}$ ed. Guaíba, Livraria e Editora Agropecuária. 360p.

Fornasieri Filho D (2007) Manual da cultura do milho. Jaboticabal, Funep. 576p.

Forsthofer EL, Silva PRF, Strieder ML, Minetto T, Rambo L, Argenta G, Sangoi L, Suhre, E \& Silva AA (2006) Desempenho agronômico e econômico do milho em diferentes sistemas de manejo e épocas de semeadura. Pesquisa Agropecuária Brasileira, 41:399-407.

Gardner FP, Pearce RB \& Mitchell RL (1985) Physiology of crop

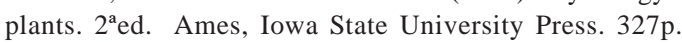

Guimarães DP, Sans LMA \& Moraes AVC (2002) Estimativa da área foliar de cultivares de milho. In: $24^{\circ}$ Congresso Nacional de Milho e Sorgo, Florianópolis. Anais, EMBRAPA/ CNPMS. p.96.

Maguire JD (1962) Speeds of germination - Aid selection and evaluation for seedling emergence and vigor. Crop Science, 2:176-177.
Mundstock CM \& Silva PRF (2005) Manejo da cultura do milho para altos rendimentos de grãos. $1^{\mathrm{a}} \mathrm{ed}$. Porto Alegre, Evangraf. $51 \mathrm{p}$.

Quiessi JA (1999) Rendimento de grãos e características agronômicas da cultura do milho (Zea mays L.) em função de cultivares e épocas de semeadura. Tese de Mestrado. Universidade Estadual Paulista, Botucatu, 94p.

Sangoi L, Almeida ML, Lech VA, Gracietti LC \& Rampazzo, C (2001) Desempenho de híbridos de milho com ciclos contrastantes em função da desfolha e da população de plantas. Scientia Agricola, 58:271-276.

Silva PRF, Argenta C, Carmona RC \& Rezera F (1996) Respostas de genótipos de milho à densidade de plantas em três épocas de semeadura. In: $21^{\circ}$ Congresso Nacional de Milho e Sorgo, Londrina. Anais, EMBRAPA/ CNPMS. p.204.

Silva PRF, Argenta G \& Rezende F (1999) Resposta de híbridos de milho irrigado à densidade de plantas em três épocas de semeadura. Pesquisa Agropecuária Brasileira, 34:585-592.

Stone PJ, Sorensen IB \& Jamieson PD (1999) Effect of soil temperature on phenology, canopy development, biomass and yield of maize in a cool-temperate climate. Field Crops Research, 63:169-178.

Viegas GP \& Peeten H (1987) Sistemas de produção. In: Paterniani E \& Viegas G. (Eds.) Melhoramento e produção do milho. Campinas, Fundação Cargill. p.451-538.

Yuyama K, Sousa ALB, Coelho ECS, Silva IA, Pereira BG, Menezes JMT, Leandro RC \& Falcão NPS (2006) Efeito da época de plantio de cultivares de milho no cerrado de Humaitá-Am. In: $21^{\circ}$ Congresso Nacional de Milho e Sorgo, Belo Horizonte. Anais, EMBRAPA/ CNPMS. CD-ROM. 